\title{
Devenires sexo-genéricos y conversión religiosa en una iglesia neopentecostal de Montevideo
}

\author{
Sexual and gender becomings and religious conversion in a neo-Pentecostal \\ church in Montevideo
}

\author{
D Magdalena Milsev Santana \\ magdalenams610@gmail.com \\ Universidad de la República, Uruguay
}

Recepción: 01 Marzo 2021

Aprobación: 23 Junio 2021

Publicación: 01 Septiembre 2021

Cita sugerida: Milsev Santana, M. (2021). Devenires sexo-genéricos y conversión religiosa en una iglesia neopentecostal de Montevideo. Descentrada, 5(2), e146. https://doi.org/10.24215/25457284e146

\begin{abstract}
Resumen: A partir de la etnografía desarrollada en una iglesia neopentecostal de Montevideo, se abordan aquí relatos que refieren a la conversión religiosa desde una perspectiva de género. Partiendo de un abordaje narrativo de dicho proceso, se considera que el mismo implica la adopción de un relato de vida religioso, la transformación del propio cuerpo y especialmente de la sexualidad, conforme a los referentes simbólicos y las disposiciones morales propuestas por la iglesia. Viéndose en este fenómeno una de las dimensiones en las cuales las imbricaciones religión-política se expresan en este contexto.
\end{abstract}

Palabras clave: Conversión, Género, Sexualidad, Neopentecostalismo.

\begin{abstract}
Based on the ethnography developed in a neoPentecostal church in Montevideo, stories that refer to religious conversion are addressed in this work, from a gender perspective. This process implies the adoption of a religious life story, the transformation of the own body and especially of sexuality, according to the symbolic referents and moral dispositions given by the church. Seeing in this phenomenon one of the dimensions in which the imbrications religion-politics are expressed in this context.
\end{abstract}

Keywords: Conversion, Gender, Sexuality, Neopentecostalism.

\section{INTRODUCCIÓN}

El presente artículo se propone abordar relatos que refieren a la conversión religiosa, entendida como un proceso de constitución identitaria, que involucra especialmente a la sexualidad y su transformación. ${ }^{1}$ Se parte de la labor etnográfica llevada adelante desde junio de 2018 a julio de 2019 en el templo principal de la iglesia neopentecostal Misión Vida para las Naciones y un Hogar Beraca - "obra social” de la misma- en la ciudad de Montevideo.

Tal abordaje se realizará desde una perspectiva de género, considerada relevante para comprender cómo se constituyen diferencialmente las subjetividades religiosas en este contexto. Se entiende al género como un "proceso activo que articula múltiples aspectos de la vida social, entre ellos la experiencia religiosa" que siempre es "la experiencia de los hombres y las mujeres, y en ninguna sociedad conocida esa experiencia es la misma” (Bynum 1986, en Tarducci 2001, p. 100). 
Este carácter generizado del fenómeno de conversión, se considera a su vez en continuidad con el activismo político llevado adelante por la iglesia. En este sentido, es de destacar que Misión Vida ha protagonizado en el país las campañas opositoras a los proyectos legislativos y educativos en materia de derechos sexuales y reproductivos. Es a su vez, hasta el momento, la única iglesia en Uruguay que ha empleado exitosamente su aparato institucional para acceder a posiciones en el gobierno. ${ }^{2}$

En este contexto, se considera a la conversión como un fenómeno cuyo abordaje resulta fundamental para la comprensión del carácter político del movimiento neopentecostal, en tanto proceso constitutivo de diferencias en el campo social y en este caso, de subjetividades religiosas políticamente movilizadas. Como señala Marcos Carbonelli (2014, p. 509) el "trabajo institucional sobre la subjetividad de los creyentes" puede considerarse la dimensión política de mayor relevancia en el espacio evangélico, teniendo a su vez presente el papel de las emociones religiosas "en su capacidad histórica de fundar comunidad y producir esquemas de interpretación del mundo social que dotan de sentido a la experiencia” (Algranti, 2007, p. 373).

En el marco de la imbricación religión-política en este contexto, la dimensión género/sexualidad resulta entonces un aspecto central a considerar, en tanto eje sobre el cual se distribuye diferencialmente el poder, se asignan roles, se constituyen identidades, y se incorporan disposiciones morales que movilizan políticamente a los sujetos.

El género, entendido como "elemento constitutivo de las relaciones sociales basadas en las diferencias percibidas entre los sexos" y como "forma primaria de relaciones significantes de poder" (Scott, 1996, p. 289), nos lleva a atender cómo tal estructura de significados atraviesa los cuerpos, constituye subjetividades, y asigna posiciones específicas en la jerarquía de la iglesia y la familia. Es importante destacar el carácter complejo y ambiguo de estos procesos, en tanto tales representaciones no se encuentran en una relación de total correspondencia con la distribución de carisma -de poder- en el contexto de la comunidad religiosa.

En este sentido, para no caer en simplismos en torno a "las mujeres" a representar, cabe considerar la importancia de una perspectiva interseccional, que incluya los ejes étnico-racial y de clase, teniendo presente que las fieles neopentecostales no suelen provenir de los mismos sectores sociales que las académicas de clase media que "las estudian".

En esta línea, se siguen aquí las reflexiones planteadas por Saba Mahmood (2005), en cuya investigación sobre las mujeres musulmanas involucradas en el "Movimiento de la Piedad" plantea los desafíos para abordar desde el feminismo la adscripción femenina a movimientos explícitamente patriarcales. En ellos puede observarse, por un lado, la presencia de mujeres en posiciones tradicionalmente ocupadas por hombres, y por otro, que las mismas expresiones empleadas para alcanzar tales lugares se basan en los discursos que históricamente han sostenido la subordinación a la autoridad masculina (Mahmood, 2005, p. 6). En este sentido, problematiza la universalización de la aspiración emancipatoria del feminismo, subyacente en los enfoques académicos que recurrentemente buscan encontrar estrategias de "resistencia" y autonomía femenina en contextos de "opresión". Recupera a referentes del feminismo afro que ya en los setenta señalaban la necesidad de atender a las dimensiones estructurales de opresión étnica y de clase que implican otras formas de habitar y desarrollar estrategias de supervivencia; en conjugación con la perspectiva postestructuralista de Michel Foucault y Judith Butler sobre la "agencia” y su relación con el poder y la subjetivación.

Entendiendo al poder no como mera dominación, sino como relación estratégica de fuerza que permea la vida y es productiva de formas de deseo, objetos, relaciones y discursos, se considera su carácter "positivo", en la constitución de sujetos. El sujeto no precede a las relaciones de poder en forma de consciencia individuada, sino que siempre es producido por estas relaciones, las cuales constituyen las condiciones necesarias para su posibilidad de existencia. Siendo central para esta formulación la paradoja de la subjetivación: los mismos procesos y condiciones que aseguran la subordinación de un sujeto, son también los medios por los cuales este se vuelve una identidad auto-consciente y un agente (Butler, 1993; 1997, Foucault, 1980; 1983, en Mahmood 2005, p. 18, traducción propia). 
En este sentido, la agencia, en tanto capacidad de reflexión, acción y crítica, constituye una dimensión de la subjetividad siempre sujeta a las estructuras de poder que constituyen al sujeto como tal, y por lo tanto difiere considerablemente conforme al contexto sociocultural en cuestión (Ortner, 1995).

Siguiendo a Mahmood, dicha capacidad no implica únicamente el acto de "resistir", sino las múltiples formas en las cuales se habitan las normas, siendo importante el interrogar las condiciones prácticas y conceptuales bajo las cuales diferentes formas de deseo emergen, incluyendo el deseo a someterse a una autoridad reconocida (2005, p. 15).

Llevado al contexto occidentalizado del Río de la Plata, tales observaciones nos llevan a pensar la presencia mayoritariamente femenina en las filas de movimientos religiosos conservadores, donde las consignas antigénero se han vuelto parte central de los discursos opositores a los derechos sexuales y reproductivos.

El carácter "autoritario" o en principio "contrario a los intereses" de los sujetos que acuden a estos espacios, implica un desafío para el pensamiento feminista semejante al planteado por Saba Mahmood, más aún teniendo presente que quienes investigan forman parte de la misma sociedad que quienes defienden estas "agendas patriarcales", encontrándonos en las antípodas en el marco de las contemporáneas disputas por derechos.

El lugar de "frontera" que se llega así a habitar en el contexto del diálogo en territorio, se encuentra así cargado de ambigüedad y conflicto, corriéndose los riesgos de juzgar a dichas expresiones religiosas por sus discursos opresivos, y de invisibilizar el carácter eminentemente subalterno del fenómeno, y especialmente de las mujeres que lo abrazan como expresión religiosa identitaria.

\section{EL CONTEXTO}

La iglesia Misión Vida para las Naciones (MVN) es una de las mayores instituciones de su tipo en el país, contando en la actualidad con dieciséis templos alrededor del territorio nacional, cuatro más en Argentina, Brasil y Chile, y una feligresía que ronda las doce-quince mil personas.

De orígenes argentinos, esta emergió como una escisión de la iglesia Ministerio Ondas de Amor y Paz arribada a Uruguay en $1989,{ }^{3}$ teniendo de este modo, una raíz diferente a la de otras expresiones neopentecostales existentes en el país, mayormente influenciadas por la corriente brasileña.

Las prácticas y expresiones rituales de MVN resultan contrastantes con las de dicha expresión religiosa. La clásica categoría "neopentecostalismo" planteada por Ari Oro se corresponde con lo visualizado en este contexto, a partir de las apreciaciones realizadas por Alejandro Frigerio (1994) a propósito de lo que el autor categoriza como "neopentecostalismo argentino", tales como la menor exigencia de ofrendas monetarias a nivel ritual y un discurso de guerra espiritual más amplio, no centrado en las religiones de matriz afro.

En este sentido, es de destacar a su vez que, mientras iglesias brasileñas como la IURD se caracterizan por el uso de objetos como mediadores de lo religioso (“jabón de la descarga”, “aceites consagrados”, sales), como resultado de la "umbandización" de los nuevos movimientos religiosos en Brasil (Bastian, 1997, p. 76), la expresión neopentecostal presente en MVN no sigue este tipo de prácticas, e incluso puede decirse que las rechaza.

A nivel de estructura institucional, MVN funciona siguiendo un modelo piramidal donde la máxima autoridad es el apóstol Jorge Márquez, seguido de su esposa, la pastora Marta Molina, fundadores de la iglesia. Jerárquicamente, les siguen unos veinte pastores y pastoras principales, que dirigen el resto de los templos y se encuentran a cargo de diferentes áreas geográficas; los diáconos (potenciales pastores); y finalmente los y las colaboradoras y voluntarias que ayudan en diferentes tareas, siguiendo las órdenes de los pastores zonales (recibir a fieles en el templo, recoger las ofrendas en las ceremonias religiosas, limpiar, etc.).

En tal contexto, una figura institucional de relevancia es «la célula», un grupo de unas veinte-veinticinco personas a cargo de dos o tres referentes de la iglesia, una modalidad de reunión que provee de instancias de 
sociabilidad y encuentro cercano entre los miembros de la comunidad, permitiendo el desarrollo de vínculos más cercanos entre los asistentes.

De acuerdo con sus líderes, esta organización institucional es inspirada por un orden bíblico y ninguna formación teológica es necesaria para el ejercicio de los cargos religiosos. Es el “apostolado” la expresión más elaborada de esta autoridad basada en el carisma (Weber, 2004, p. 172), según la cual se considera a Márquez un enviado de Dios, cuyo poder no responde a "la mundanidad de las certificaciones académicas".

En lo que respecta a la población que asiste a MVN, puede decirse que la misma se caracteriza mayormente por pertenecer a sectores precarizados de la sociedad, encontrándose esto vinculado al trabajo que la iglesia lleva adelante entre los sectores más desfavorecidos a través de su obra social, los Hogares Beraca. Estos últimos, como parte de la ONG ESALCU (espíritu, alma, cuerpo) -estrechamente asociada a la iglesia, aunque no a nivel legal- a través de un sistema que conjuga lógicas comunitarias con las de las "instituciones totales" ${ }^{4}$ (Goffman, 2001, p. 13), alojan a sujetos en situación de vulneración que no han sido alcanzados eficazmente por las políticas estatales, acudiendo a estos espacios especialmente por consumo problemático de sustancias y violencia de género.

Formalmente, la existencia de estos espacios se remonta a las "Comunidades Beraca", fundadas en el año 2002 en el marco de una fuerte crisis económica y social vivida en Uruguay, si bien es de destacar que desde la década anterior los pastores recibían a personas en situación de calle en sus casas. Actualmente, se tienen sesenta y cuatro Hogares, cincuenta y tres en Uruguay (doce en Montevideo y cuarenta y uno en el interior del país), y once más distribuidos en Argentina, Chile, Brasil y Haití. ${ }^{5}$

Se tienen así Hogares de hombres, de mujeres, y de madres con hijos, donde cada uno de estos se dedica a actividades económicas distintas, tales como panificación, producción textil, serigrafía, trabajo rural, carpintería, herrería, etc. con el fin de auto-sustentarse, si bien en algunos casos los hogares más prósperos donan a aquellos con más dificultades. De esta labor social desempeñada por la iglesia, se tiene consecuentemente la marcada línea de clase a través de la cual crece el fenómeno neopentecostal, en este caso, viéndose una preeminencia de trayectorias de vida atravesadas por múltiples formas de violencia.

\section{La iglesia Misión Vida para las Naciones desde una Perspectiva etnográfica}

El presente texto parte metodológicamente de los procesos etnográficos llevados adelante desde junio de 2018 a julio de 2019 en el templo principal de la iglesia Misión Vida para las Naciones, ubicado en la zona de Tres Cruces de Montevideo, y en el Hogar Beraca para Madres con Hijos del barrio La Unión. Allí, a su vez, funciona la sede central de la ONG ESALCU (Espíritu, Alma, Cuerpo), de la cual depende.

La elección de estos espacios para desarrollar el trabajo de campo estuvo dada por el protagonismo que MVN ha tenido en los últimos años en la activa oposición a los proyectos legislativos y educativos vinculados a la agenda de derechos sexuales y reproductivos, así como a su involucramiento en la política partidaria del país. En este contexto, los discursos relativos a género y sexualidad resultaron predominantes, dado los debates que le fueron contemporáneos, tanto en Uruguay como en Argentina, y en los cuales la iglesia participó activamente como actor opositor. Así, fue posible realizar un seguimiento de este activismo en el caso particular de la campaña para derogar la Ley Integral para Personas Trans aprobada por el Parlamento uruguayo en 2018.

Aborto, "ideología de género", transexualidad, homosexualidad y demás proscripciones sexuales, emergían así en el marco de sermones e intercambios cotidianos en la iglesia y en Beraca, siendo por ello el abordaje de estos temas un asunto ineludible desde una perspectiva etnográfica sensible a los discursos de las y los interlocutores en contexto.

Teniendo presente el carácter reaccionario que dicho posicionamiento político posee en el ámbito de pertenencia de quien investiga, es que resulta particularmente conveniente el mantener una perspectiva 
dialógica y polifónica (Abélès y Badaró, 2015; Clifford, 1998) que permita acceder a los sentidos elaborados por los sujetos en sus propios términos.

Esto se considera en línea, a su vez, con el llamado "enfoque narrativo en Antropología”, el cual al desdibujar "las distinciones entre relato objetivo y subjetivo, real e imaginario", ayuda a "comprender las relaciones entre producción narrativa, sujeto, grupo social y formación cultural” (Jimeno, 2016, p.9).

Las narraciones a abordar aquí -relatos de conversión- conllevan, por otra parte, diferentes niveles de "opacidad" en tanto cumplen, por un lado, cierta funcionalidad en el contexto religioso, y por otro, implican procesos de subjetivación cuyo desencadenamiento resulta insondable en un estudio sincrónico.

Los relatos de conversión constituyen "autobiografías", en tanto los sujetos desarrollan desde su perspectiva religiosa actual, una revisión evaluativa de su vida, remontándose a un pasado remoto en la identificación de elementos que "les llevaron" a convertirse. Y en este sentido, por más que surjan en el diálogo de forma relativamente espontánea, estas se encuentran siempre "restringidas" por los "requerimientos de la historia" en proceso de construcción (Bruner, 2006, p.128).

En el presente caso, estos “requerimientos” están ligados, por un lado, a la práctica ampliamente extendida de leer la Biblia en este contexto, donde puede percibirse cierta coherencia discursiva entre el género narrativo bíblico y el del relato de conversión. Y por otro, al valor religioso otorgado a los testimonios, en tanto prueba de la acción de Dios en el mundo.

El abordaje de dichos relatos debe atender, por otra parte, a una opacidad aún más profunda, en tanto las narraciones de conversión no solo constituyen un producto de los procesos de subjetivación que los sujetos han atravesado, sino que son parte constituyente de tales procesos: "El relato de la sujeción es inevitablemente circular, puesto que presupone al mismo sujeto del que pretende dar cuenta" (Butler, 2001, p. 22).

La situación previa a la conversión resulta así incierta, en tanto una vez que el sujeto ha comenzado a reinterpretar su vida en clave neopentecostal, desarrolla un proceso de reelaboración y selección de experiencias desde esta perspectiva, pudiéndose sólo atisbar ciertos aspectos clave de ese "anterior yo" previo a la conversión.

\section{CONVERSIÓN RELIGIOSO-SEXUAL}

En términos generales, se entiende aquí por "conversión religiosa” a un proceso reflexivo a través del cual los sujetos transforman su identidad, apropiándose de forma creativa de referentes simbólicos propuestos por la iglesia y sus discursos. Siendo dicha experiencia transmitida a través de relatos, en cuya constitución se desarrolla una re-significación neopentecostal de la propia vida.

Dicha re-significación, si bien llega a expresarse como un "corte" en la propia biografía -con un claro "antes y después"- en los hechos constituye un fenómeno procesual, en tanto transformación identitaria siempre inacabada y en permanente revisión, que involucra necesariamente el ejercicio de reflexión en el marco de una trayectoria de búsqueda de sentido (Carozzi y Frigerio, 1994).

En esta línea, siguiendo la perspectiva del converso como sujeto activo (Carozzi y Frigerio, 1994, p. 3), se considera que, en dicho proceso, el sujeto en cuestión no constituye un ser pasivo al cual lo religioso imprime una concepción del mundo de forma "abrupta" o mecánica. Al contrario, a través de procesos reflexivos el sujeto va optando por transformar su propia identidad, pudiendo desarrollarse los procesos inversos de desafiliación o "deconversión" como parte de la trayectoria (Frigerio, 2002, p. 9).

Esta transformación identitaria involucra necesariamente al cuerpo como parte constituyente de la subjetividad, por lo que puede ser considerada la "búsqueda de un habitus" (Austin-Broos, 2003, p. 2) que, dependiendo de la tradición religiosa o espiritual, tendrá características particulares según el énfasis dado a determinados aspectos de la subjetividad en construcción. En este sentido, en el presente contexto resulta central a nivel del cuerpo la gestión de la sexualidad, como parte de "la nueva orientación evangélica hacia el 
'mundo' que exhorta a la ascética intramundana activa con el fin de redimir a la Creación y extender el Reino de Dios” y que “deja atrás el modelo misionero de huida ascética del mundo" (Mosqueira, 2014, p. 201).

La moral sexual se encuentra enmarcada así en una concepción más general de la realidad, donde el cuerpo, en tanto "sistema simbólico natural" (Douglas, 1978) se vuelve, a su vez, un ámbito privilegiado de expresión de los valores del grupo, a través del establecimiento de límites a las experiencias permitidas conforme a cierta interpretación literal de los textos bíblicos, según la cual se asimila sexualidad a genitalidad.

En esta línea, los órganos sexuales y reproductivos constituyen el "fundamento" de una definición identitaria heterosexual, donde el desvío de esta norma no solo constituye un pecado que obstaculiza la salvación, sino un acto "contra-natura" que provoca problemas de salud.

Se destaca así, la articulación entre el género definido en términos religiosos y un discurso fuertemente biologicista, donde se apela a "la ciencia" como legitimadora de la concepción religiosa. Se buscan, de este modo, respuestas que "confirmen" científicamente los mandatos ligados a la lectura literal de los textos bíblicos, siendo ciertas enfermedades, "pruebas empíricas" de la verdad última de los mismos.

En este sentido, durante una entrevista mantenida con los fundadores de MVN, el “apóstol” Jorge Márquez afirmaba a propósito de un joven de la iglesia autodefinido como "ex - trans":

Este chico está sufriendo las consecuencias de la vida que tuvo, que gracias a Dios no tiene un cáncer ahí en el recto. Pero que lo van a tener que operar... siete años de prácticas homosexuales. Tiene consecuencias de cuatro meses de hormonización, hoy le han dado los resultados y hoy mismo le han dicho que lo van a operar... Se ve que por las relaciones que él tenía le han salido unas durezas dentro del ano. Y parece que ha quedado demostrado que no son... porque el virus del papiloma humano viene de las relaciones anales, de las relaciones bucales, las expectativas de vida de esta gente es muy baja. Y él tiene amigos que ya están muertos... Entonces combatimos eso, no es por combatir la persona, sino una clase de vida que no le hace bien a ellos. (Entrevista a Jorge Márquez y Marta Molina, agosto de 2018).

La "conversión religioso-sexual" remite entonces en este contexto, a la transformación integral a nivel de la subjetividad, que se desarrolla a través de la incorporación de los referentes simbólicos neopentecostales relativos a la sexualidad. Allí se observa que la constitución del género se performatiza en relación a un modelo original bíblico (Butler en Mafra, 2012, p.145), siendo las y los fieles neopentecostales testigos e "imitadores" de Cristo.

En esta línea, siguiendo a Butler, una de las características centrales de la conversión religiosa en contextos pentecostales y neopentecostales, es el "descubrimiento del género" que realizan las fieles, quienes comienzan a concebirse a sí mismas como mujeres en base a un dualismo procesual sobre la promesa futura de la relación a establecer con un cónyuge (Butler en Mafra, 2012, p. 145).

En los relatos, se encuentra que el abandono de ciertas prácticas -relaciones sexuales extramaritales, masturbación, pornografía, prostitución, homosexualidad, etc.- aparece asociado a la constitución de una nueva experiencia de género, elaborada en términos de una complementariedad de sexos jerarquizada, ligada al nuevo proyecto de vida neopentecostal. Esto lleva a reafirmar los atributos femeninos tradicionales que, entendidos en una relación de oposición con respecto a "lo masculino", constituyen aquí la única forma válida de vivir la sexualidad conforme a la Palabra.

\section{DeveniRes}

Teniendo presente lo anterior, se abordarán a continuación dos relatos que refieren especialmente a la transformación identitaria religiosa como una transformación de género. Cabe destacar que dicha cuestión no resulta un fenómeno privativo de los dos casos a detallar, sino que se presenta de forma persistente en el contexto de MVN, expresándose especialmente en la existencia de instancias específicas y espacios de asociación paralelos a la institución dedicados a la gestión de la sexualidad.

El primer relato a abordar es el de "Luisa", una joven afro-venezolana de treinta y un años, líder de célula, que al arribar a Uruguay -seis años atrás al momento de la entrevista-, sufre violencia de género por parte de un 
hombre con quien mantenía un vínculo sexo-afectivo, tras su oposición a que ella interrumpa un embarazo. Según el relato, es en tal contexto que comienza a asistir a la iglesia, encontrándose allí con el acceso a "la verdad" de sus pecados -"ser una asesina"- pero también con la "paz" de sentirse "perdonada" por los mismos.

El segundo es el de "Noelia", una mujer de aproximadamente la misma edad, miembro del "Grupo Boomerang" al cual pertenecen los feligreses de la iglesia MVN que se autodefinen como "ex LGBT+", quien según expresa, es motivada a participar de un evento religioso en Beraca durante una etapa de fuerte crisis existencial, teniendo dicha crisis su "resolución" una vez que, convertida al neopentecostalismo, deviene heterosexual.

Ambos casos, además de tener en común la vinculación a la iglesia en momentos de fuertes crisis morales -"moral breakdown"- (Zigon, 2007, p.138), tienen como aspectos coincidentes el sufrimiento asociado a experiencias sexo-genéricas particularmente rechazadas por la cosmología neopentecostal de MVN, y el procesamiento de las mismas a través de la apropiación de los discursos patriarcales de la institución. Esto resulta algo contrastante con las perspectivas que han visto en la aproximación femenina a grupos conservadores, respuestas estratégicas a crisis en la vida doméstica familiar (Campos Machado, 2005; Chong, 2006; Martin, 2003; Tarducci, 1994; 1999; 2001).

Sin desmerecer la importancia que tal accionar estratégico pueda tener en este contexto -y que de hecho se considera lo tiene- lo que se encuentra aquí es que el mismo no resulta el único motivo de acercamiento, siendo esto especialmente notorio en las capas etarias de mujeres jóvenes que no son madres o esposas, y que han rechazado tales roles tradicionales.

Luisa: Yo llegué, esa angustia era porque yo estaba dejando una relación que me había dejado un embarazo y yo antes de esa relación formal le dije a esa persona que no quería tener niños, que no quería salir embarazada. Estuve con esta persona, no me cuidó, salí embarazada, y cuando yo me entero que estoy embarazada yo estaba determinadísima a que no iba a tener niños. Esta persona antes me apoyaba, pero cuando le digo que estoy embarazada que no quiero tener el niño, me dijo como que "Sí, vamos a tenerlo" y yo como que "no", entonces era una lucha como entre sí, no, sí, no, y yo tomé la decisión de seguir adelante con el aborto.

Donde trabajaba me ayudaron para encontrar los medios para no tener... yo estaba segurísima de eso, no tenía ningún temor ni nada, estaba convencida de que yo no quería ser mamá. Cuando yo me hago el aborto, caigo en una depresión y angustia y este hombre me persigue por todo Montevideo, de madrugada, me vigila... entonces justamente yo venía a la iglesia y él me perseguía en su auto, yo venía con unos chicos que me traían y él me perseguía, entonces podrás imaginar que fue una situación bastante dramática y ihorrible!

Emocionalmente estaba destruida, bueno, después del episodio del aborto, claro, yo llegó un momento que no comía, no quería relacionarme con las personas, yo llegué al punto de que no quería a los hombres, yo no me quería casar, no quería tener hijos, no quería nada, (...) incluso pensé muchas veces en quitarme la vida porque no le encontraba ningún tipo de sentido.

De niña yo consumí mucha pornografía, masturbación, entonces vine toda rota. Deshecha. Entonces esa angustia se sumó a la persecución que estaba viviendo. Por ningún lado que yo veía, veía alguna luz, todo veía oscuro, incluso sentía que tenía una venda en mis ojos, cuando yo vengo a este lugar yo siento que se rasga un velo literalmente. Yo empiezo a ver que yo había matado a un niño, no solamente acá, que yo me hice dos abortos, uno en Venezuela y uno acá. Ahí yo asumo que yo había sido una asesina, y en eso que se me rasga el velo, asumo todos los errores que cometí, pero también veo la vida que viví, y que muchas de las cosas eran cosas que yo había permitido y otras que yo no había permitido que ocurrieron y que me llevaron a... Yo llegué al punto que odiaba a los hombres, yo salía con ellos para hacerles daño, ¿me entiendes? (...) (Fragmento de entrevista a "Luisa”, líder de célula, 2018).

El citado fragmento refleja la adopción del discurso de la iglesia en torno a la figura doctrinaria del "Hombre Nuevo", pudiéndose distinguir una serie de "hitos", donde destaca especialmente el momento de "quiebre" con la identidad previa a la conversión y su estilo de vida, en el cual sucede la re-significación del pasado conforme a la nueva cosmovisión adoptada.

En lo que respecta al sentimiento de culpa expresado, puede decirse que, además de responder a la matriz judeocristiana que todo lo permea en nuestra sociedad -y por lo cual puede intuirse previo al involucramiento con la iglesia-, el mismo se ve intensificado una vez que la mujer inicia su proceso de conversión en MVN. Tales disposiciones morales promovidas por la iglesia, son reafirmadas constantemente a través de prácticas rituales de confesión pública y brindar testimonio. 
Ahora bien, suponiendo que los sujetos no van en contra de sus "propios intereses", ¿cómo es que Luisa es admitida y logra sentirse "feliz" en un contexto en el cual es considerada una "asesina"?

Siguiendo a Veena Das (1997), "las instituciones sociales están profundamente implicadas en dos modos opuestos: el de la producción de sufrimiento y el de la creación de una comunidad moral capaz de lidiar con él” (p. 437).

Según lo expresado, durante el proceso de conversión, la mujer comenzó a incluir en su marco interpretativo a los referentes simbólicos propuestos por la iglesia, comenzando a sufrir en tales términos y alcanzando finalmente a través de los mismos una "reconciliación” consigo misma.

Teniendo presente las disputas sociales en torno a los sentidos del aborto -donde sus detractores no necesariamente expresan oposición en términos explícitamente religiosos- y la persecución vivida por Luisa por parte de su ex pareja, cabe considerar que el sentimiento de culpa al respecto de este tema fue incluso anterior a su involucramiento con la iglesia. Cuestión que se vuelve aún más plausible si se considera que "la conversión suele basarse en fuertes creencias preexistentes" (Sachs Norris, 2003, p. 172).

Siguiendo a Rebecca Sachs Norris (2003), cuando el potencial converso descubre en la nueva cosmovisión las respuestas que intuía de antemano, comienza a desarrollarse el proceso de asimilar el nuevo sistema de creencias y prácticas de la expresión religiosa adoptada.

En un sentido similar, en las narrativas de conversión presentes en este contexto se encuentra la referencia a momentos de sufrimiento que devienen en un "quiebre moral", previo al primer involucramiento con la iglesia, apareciendo esta como la única "solución” socialmente disponible para la/el converso en esa circunstancia. La conversión religiosa aparece como una respuesta reflexiva a momentos de ruptura o "crisis moral" (Zigon, 2007), en los cuales el sujeto siente sobre sí una demanda ética que pone en cuestión sus habituales disposiciones morales, su cotidianidad moral.

En el caso de Luisa, este proceso habría implicado una re-significación del propio cuerpo, especialmente de su capacidad reproductiva, implicando así la transformación no solo de su interpretación sobre el aborto, sino también el sentido de la propia existencia, entendiendo a la maternidad como un mandato divino conforme a los preceptos bíblicos, y por lo tanto, como un proyecto de vida ineludible.

M: ¿Cómo fue el proceso de cambiar tu interpretación en relación al aborto?

Luisa: Claro, porque yo empecé a entender que Dios daba vida y que yo en un momento estando viva me encontraba muerta por dentro porque no quería dar vida. Y ahí cuando Dios empieza a hablarme a través de su palabra, que él es el camino de la verdad y la vida, y yo justamente había matado una vida, entonces yo digo "Creo que tú me haces bien, Dios, creo que leer la Palabra me hace bien. Creo que lo que yo sentí en el pasado de no dar vida, está bloqueando algo que tú estableciste". He ahí cuando cambio mi pensamiento y digo, "Ta, ahora quiero ser madre". Pero fue un proceso más o menos como de un año (...) A mí todo el tiempo me venía una culpa, acusaciones, venía todo el tiempo una vocecita que me decía "Eres una asesina mataste a dos niños, te vas a ir al infierno". Y yo decía, pero si yo estoy buscando a Dios, ¿por qué siento esa vocecita?

M: ¿Y cómo te ayudaron acá con ese tema?

Luisa: Conocí rápidamente a la pastora de la zona donde yo estoy. Cada vez que me venía una crisis de estas que te digo (...) yo lo hablaba con ella. Le decía, "Me siento así, me siento asá", y ella oraba por mí, o me decía "Mira, es mentira, eso es mentira de tu mente, Dios dice que tú eres amada, eres perdonada” y me llevó a la Biblia, a un capítulo de la Biblia en Romanos 8 que dice que "No hay condenación para los que están en Cristo Jesús". Entonces cuando yo leí eso [su tono de voz cambia, se emociona], ella me lo hace ver, entonces yo digo “¡Yo estoy en Cristo, yo lo acepté!”, entonces ahí vino un perdón más genuino, un perdón más profundo, ¿entiendes? (Fragmento de entrevista a "Luisa”, líder de célula, 2018).

Por otra parte, el caso del devenir heterosexual de "Noelia" vía conversión religiosa, también puede plantearse en estos términos, dado el carácter disruptivo de la homosexualidad en nuestra sociedad, pese a los derechos alcanzados por el colectivo LGBT+. Ahí, la iglesia MVN aparece como un dispositivo de reorientación de la sexualidad en momentos de crisis de identidad.

Noelia: ${ }^{6}$....llegué con pensamientos negativos, sin ganas de vivir, depresión, pero bueno, tuve un encuentro con Dios y ahí encontré mi verdadera identidad. Bueno para contarles más o menos un poco. Mi testimonio comienza cuando yo tenía más o menos ocho años que iba a la escuela y ya tenía pensamientos de que yo había nacido varón, ya me gustaba jugar a la pelota, 
no me gustaban las muñecas, me gustaba siempre andar con varones, nunca con chicas, siempre andaba así y cuando llegaba a casa yo no tenía una madre que me dijera que yo tenía falta de identidad. Eso estaba totalmente prohibido hablar de la sexualidad, hablar en los términos de... a mí por ejemplo nunca me dijeron cómo iba a ser la primera vez que yo estuviera con un chico, nunca me dijeron que yo me tenía que maquillar y bueno, así me fui criando.

Me fui criando acorde a las salidas que yo tenía en el liceo, acorde a las salidas que yo tenía con amigas, yo a la edad de trece años, en el liceo uno se plantea como joven, como adolescente, el amor. Así que bueno con la edad de trece años me enamoro de un chico, estuve en ese momento que estaba enamorada así que bueno salgo con él, y tengo mi primera experiencia sexual con él, mi primera relación sexual. Y se me fue lo más sagrado que tenía yo lo veía como que era algo normal, como que bueno la sociedad es así, esto es el amor (...)

Hasta que con dieciséis años yo conozco una chica y le empiezo a contar que yo tengo pensamientos así, y me enamoro y empiezo una relación homosexual con esta chica. Y bueno, yo me hice lesbiana, empecé a vestirme como varón, no tenía rumbo, no tenía bien lo que era ser mujer y lo que era ser varón. Ya que para nosotros hoy en día, la gente del día, la gente del mundo, es totalmente normal ser lesbiana. Para mí era normal ser lesbiana, llegó un punto que bueno, que yo estoy ahí con esa chica y ella me invita a casarme. Después de años de relación estoy a punto de casarme pero como no estaba el matrimonio igualitario todavía legalizado yo quería viajar a España para poder casarme, pero cuando ella me da las alianzas no me quiero casar. Hay algo en mí que no está bien. En el momento que estaba logrando lo que toda mujer quiere, que es casarse y formar una familia, yo sentía que había algo en mí que no estaba bien. Siempre estaba ese vacío. Entonces yo me peleo con ella.

Y ahí yo me voy a la casa de mis padres, porque yo hacía dos años que estaba viviendo con ella, y ahí en la casa de mis padres viene una chica y me predica de Dios. Y bueno, lo primero que yo le dije fue "Yo voy a la reunión, te acepto". Porque la chica se me presenta y me dice "Bueno, mirá, te quiero invitar a una reunión”. Y entonces yo lo primero que le digo es "Yo soy lesbiana, tengo pareja, pero si querés voy" (...)

Nunca me discriminaron, yo había ido vestida de varón, todavía me acuerdo cómo había ido vestida, fui con un canguro, fui con un pantalón todo roto y lo más importante fue que en esa reunión no me discriminaron y yo ahí recibí el amor de Dios, el verdadero amor de Dios. (...) Y bueno, al mes, me invitaron a ir a un campamento Beraca, unas chicas de la pastora Lorna, y bueno me dice "Yo te voy a pagar el campamento", me dijo "Vos ahí vas a cambiar, yo tengo fe que Dios ahí te va a tocar".

Y como no tenía nada que perder, ya me daba igual ir a un campamento o no, fui. Fui sin expectativas de nada, fui porque me dijeron que iba a haber dos mil jóvenes. Dije "bueno, me voy a divertir, voy a jugar al futbol" que es lo que me gustaba a mí, pero más nada. (...) Y cuando yo voy a ese campamento me pasa exactamente lo mismo que en la primera reunión: me daban besos, me decían que yo era una princesa, y yo nunca había escuchado eso, ni de mi mamá, ni de mis amigas. Y bueno, cuando yo tuve un encuentro con Dios en ese momento, fue cuando yo me di cuenta que nací para ser mujer. [Las mujeres aplauden. Ovacionan].

Y no solo eso, a partir de ese momento, de ese encuentro que yo tuve con Dios me empiezo a sentir diferente, me empiezo a vestir de otra manera. Si hoy me visto así no es porque yo quiero sino porque verdaderamente es Dios, ¿̇no? El pelo yo me lo había rapado, a cero, me pelé completamente, y ahora hace cinco años... Dios me dio este pelo, porque yo no tenía el pelo enrulado [aplauden] y bueno, ahí en ese encuentro, hoy tengo ganas de vivir. La depresión se fue, tengo sueños, tengo ganas de casarme [aplauden]... y con un hombre, ojo. (Testimonio público de "Noelia", durante la jornada por el Día Internacional de la Mujer, 2019)

Como se señaló para el relato de "Luisa", en el de "Noelia" se distinguen nuevamente diferentes "hitos" que llevan a la protagonista hasta su situación actual. Se encuentra que la inquietud y crisis de identidad vinculada a su sexualidad resultan algo difusas, en tanto la mujer afirma haberse autodefinido "lesbiana" al momento de involucrarse con la institución religiosa, sin explicitarse desde una perspectiva procesual el cambio de orientación. De hecho, este es únicamente expresado en términos milagrosos: "cuando yo tuve un encuentro con Dios en ese momento, fue cuando yo me di cuenta que nací para ser mujer".

Sin embargo, lo que resulta claro en esta construcción narrativa es la asociación entre identidad religiosa e identidad sexual, donde la heterosexualidad concebida como la única forma válida de "ser mujer", pasa a ser la nueva experiencia de Noelia, su "descubrimiento del género" en términos de Mafra (2012, p. 126).

En este caso, la conversión religioso-sexual encuentra su capacidad transformadora en la "distinción entre pecado y pecador”, según la cual “[se rechaza] la práctica homosexual (pecado) y [se ofrece] 'liberación' y 'restauración' a los homosexuales (pecadores)" (Jones y Carbonelli, 2012, p. 228). Esta forma de concebir la homosexualidad es una herencia de la tradición calvinista, según la cual el cuerpo en tanto "clausura del cristiano" es "morada del Espíritu Santo", debiendo así rechazarse los placeres mundanos para que no se vuelva "morada del demonio", cuestión que favorece en este contexto, "la asociación de la homosexualidad con la posesión demoníaca” (Campos Machado, Piccolo, Zucco y Neto, 2011, p. 89). Se configura, así, una 
serie de prácticas de aceptación de homosexuales en la institución, a las cuales subyace la intencionalidad de transformar y reorientar. La acogida de homosexuales en la iglesia aparece como una "estrategia política higienista" llevada a cabo en el plano de las interacciones cotidianas, "que no golpea a los sujetos directamente con la amenaza de la violencia física, pero los antagoniza y descalifica” (Natividade y Oliveira en Biela Dias, 2019, p. 127).

De este modo, la heterosexualidad concebida como una "norma sagrada", si bien constituye una forma de rechazo a sus "otredades", es reivindicada a través de discursos de "amor al prójimo" y "perdón”, en tanto el carácter pecaminoso de sus disidencias es considerado equiparable a cualquier otro pecado que los y las fieles afirmen haber cometido en este contexto.

\section{Sobre gÉnero, AGENCIA y CLASE}

Las representaciones religiosas sobre el cuerpo sexuado en el contexto de MVN no solo vienen a reafirmar el histórico binarismo heteronormativo presente en nuestra sociedad, sino también a explicitar una jerarquía sexual donde la sumisión de la mujer a la autoridad masculina es considerada parte de un orden sagrado a respetar.

Basada en una interpretación que intenta ser literal de ciertos fragmentos bíblicos, ${ }^{7}$ esta jerarquía constituye la base a partir de la cual se concibe a la familia como una estructura en la cual los integrantes fundamentan su identidad conforme a la posición que ocupan en la misma, según los ejes diferenciales de género y generación.

La declaración de tal orden jerárquico constituye un elemento en común que los pentecostalismos y neopentecostalismos mantienen con otras iglesias del llamado "polo conservador bíblico" (Wynarckzyk, 2014). Hay que destacar que en algunas iglesias evangélicas se llega a matizar esta tendencia, a través de los liderazgos femeninos de las pastoras, cuestión que resulta clara en la iglesia abordada en el presente artículo.

Teniendo presente las controversias que esta "sagrada jerarquía" genera en una sociedad donde las reivindicaciones de equidad se han vuelto parte de una agenda global, resulta necesario contextualizar la construcción de género que se da en el marco de esta cosmología, atendiendo especialmente a los sujetos que convoca y los impactos que tiene la misma en sus vidas.

La bibliografía reseñada en este trabajo, en coherencia con lo observado durante la experiencia de campo, señala que el movimiento pentecostal desde sus inicios y posteriormente los neopentecostalismos, se han caracterizado por tener éxito entre quienes han tenido menos posibilidad de acceso al sistema educativo y capacidad de ingreso. Se destaca así, cierta coherencia entre el sistema de creencias propuesto por estos movimientos religiosos, y esquemas de pensamiento y conducta fuertemente arraigados en el "sentido común" popular latinoamericano que los ha abrazado.

Para comprender cómo es que los sujetos en este contexto adhieren y celebran relaciones de poder que desde una perspectiva moderna resultan "abusivas", se considera necesario atender no solo a lo que se dice al respecto de las normas religiosas, sino también a lo que efectivamente se hace, tratando de captar matices y contradicciones que pueden suscitarse. Por otro lado, es importante atender a la citada dimensión de clase del fenómeno, cuestión no menor considerando las formas de agenciamiento y estrategias de supervivencia aquí involucradas.

En este sentido, distintas investigaciones han señalado el carácter paradójico de las relaciones de género en grupos pentecostales y neopentecostales, con la ocurrencia simultánea de tendencias contrapuestas en lo que respecta al poder, los espacios de participación a mujeres, hombres y niños, y las posibilidades de ascenso y beneficios brindados a unos y otros.

La fundamentación paulina de la autoridad masculina, si bien se afirma en el plano discursivo, sucede simultáneamente a la participación de mujeres en posiciones de poder tradicionalmente negadas. Estos 
liderazgos femeninos son legitimados mediante la afirmación de su subordinación (Campos Machado, 2005; Mafra, 1998; Martin, 2003; Tarducci, 1999).

A su vez, la masculinidad, si bien es construida en términos abiertamente patriarcales, se presenta como menos violenta que el machismo tradicional, redituando esto en el contexto familiar, dado el carácter equitativo del sometimiento a las normas religiosas, el llamado al involucramiento activo en la familia por parte de los hombres y la resolución de conflictos intrafamiliares vía intervención colectiva (Mafra, 2012; Martin, 2003; Campos Machado, 2005; Semán, 2001; Tarducci, 1994). De este modo, en el contexto de las relaciones de género tradicionalmente definidas en términos jerárquicos, el neopentecostalismo "agrega" una instancia "equitativa" en lo que respecta al obedecimiento de las normas religiosas y el compromiso con la familia, obligando al hombre a respetar pautas de conducta que tradicionalmente solo fueron exigidas a las mujeres conforme a un doble estándar moral (Martin, 2003).

De acuerdo con Bernice Martin (2003), la "paradoja de género" se da así en la tensión irresuelta entre el sistema normativo patriarcal de la iglesia y el hogar, y el establecimiento en los hechos de una forma de vida que implica un giro decisivo en las prioridades domésticas y religiosas de los hombres en una dirección que beneficia a las mujeres y niños del grupo familiar.

Ahora bien, cabe tener presente que los ejemplos citados no se corresponden con mujeres amas de casa cuyos motivos de involucramiento con la iglesia hayan sido problemas en el contexto familiar y doméstico ( $s$ bien estos casos también se encuentran en este contexto), sino que se trata más bien de mujeres en cuyas trayectorias de vida han contemplado posibilidades abiertas por las luchas feministas y LGBT+.

En este sentido, resulta importante atender a estas experiencias presentes en generaciones más nuevas, a quienes las transformaciones contemporáneas en materia de género han logrado alcanzar, aunque de forma quizás refractaria. Estos procesos en marcha implican ciertas disrupciones y contradicciones, especialmente entre quienes se encuentran más allegadas a ámbitos conservadores.

Siguiendo a Kelly Chong (2006), el involucramiento femenino en movimientos religiosos abiertamente patriarcales es un fenómeno complejo "cuyas dinámicas particulares y efectos deben de entenderse en su particular contexto socio-histórico y régimen de patriarcado" (p. 701). Por lo que no solo las motivaciones detrás de la orientación de las mujeres al tradicionalismo, sino también las formas particulares de su compromiso religioso y sus consecuencias, deben de ser comprendidos como productos de procesos específicos de cambio social, modernidad, y de la estructura y lógica de las relaciones de género-familiares, que dan forma a subjetividades distintivas, motivaciones e intereses (Chong, 2006).

En los citados casos, así como en el de otros jóvenes feligreses, la aproximación a la iglesia y la adscripción a la oposición a la "agenda de derechos" se presenta en el marco de contradicciones propias de un "régimen de patriarcado" (Chong, 2006, p. 702) que se encuentra en mutación y reacomodación, en el contexto de un país cuya diversidad religiosa resulta aún inusitada para los sectores más secularizados.

Las conflictividades producto de las agónicas dinámicas de distinción y oposición social que se generan entre quienes reivindican la ampliación de derechos y quienes se les oponen dejan abiertas cuestiones ligadas a la posibilidad de diálogo y comprensión mutua. Se tiene especialmente presente la pertenencia de género y clase de los actores en cada caso, donde "las mujeres" aparecen como un grupo particularmente heterogéneo, en el que la brecha dada en la identificación- o no- con el feminismo, suele aparecer también como una brecha de clase.

En el marco de una sociedad occidentalizada y desigual, "las condiciones y situaciones de clase van a determinar, en parte, las posibilidades de acceso a bienes materiales y simbólicos y la preeminencia diferenciada de visiones del mundo más o menos individualistas y relacionales". Para el caso de las mujeres, la escolaridad reducida y el escaso acompañamiento en tareas de cuidado, "comprometen la movilidad entre los mundos sociales y dificultan los intercambios simbólicos con otras camadas de la sociedad, teniendo esta diferenciación de las experiencias fuertes implicaciones en el proceso de construcción de identidad de los segmentos femeninos pobres (Campos Machado y Lins de Barros, 2009, p. 70). Estas diferentes experiencias 
de género y clase implican distintas formas de agenciar, involucrando así diversos sentidos y resonancias en torno a los términos en los cuales se sostienen las reivindicaciones de emancipación, es decir, los de "libertad" e "igualdad". La agencia, en tanto capacidad de reflexión, acción y crítica, constituye una dimensión de la subjetividad siempre sujeta a las estructuras de poder que han constituido y constituyen al sujeto como tal y, por lo tanto, difiere considerablemente conforme al contexto (Ortner, 1995). En esta línea, las trayectorias reflexivas variarán considerablemente conforme a las distintas formas de represión que han atravesado y atraviesan los cuerpos según el contexto de origen, las posibilidades materiales de proyección más allá de lo doméstico, y el acceso a educación y trabajo.

\section{Conclusiones}

El presente artículo tuvo como objetivo abordar relatos que refieren a la conversión religiosa, entendida como un proceso reflexivo y siempre inacabado a través del cual se constituyen subjetividades, siendo muy importante en dicho proceso, la transformación del propio cuerpo, en este caso a través de la incorporación de las representaciones neopentecostales en torno a la sexualidad.

En tales representaciones queda reflejada la moral sexual del grupo como parte de una concepción más general del mundo y de las relaciones del ser humano con este, donde el cuerpo concebido como depositario de lo sagrado no se encuentra en una relación de total oposición a un plano "trascendente". Tal disposición moral lleva a afirmar el carácter fundante de los órganos reproductivos en la identidad y destino de los sujetos, viéndose a la función reproductora como un mandato bíblico.

Las representaciones religiosas sobre el cuerpo sexuado en el contexto de MVN no solo vienen a reafirmar el histórico binarismo heteronormativo presente en nuestra sociedad, sino también a explicitar una jerarquía sexual donde la sumisión de la mujer a la autoridad masculina es considerada parte de un orden sagrado a respetar. Se destaca, por otra parte, el desarrollo de procesos que parecen ir en dirección opuesta dada la cantidad de mujeres en posición de liderazgo, y la constitución de subjetividades masculinas más sumisas, sujetas al igual que las mujeres a estrictos códigos de conducta en lo que respecta a la vida familiar y sexual.

El carácter "autoritario" o en principio "contrario a los intereses" de los sujetos que acuden a estos espacios, implica un desafío para el pensamiento feminista, en tanto juzgar dichas expresiones religiosas por sus discursos patriarcales puede llevar a invisibilizar el carácter eminentemente subalterno del fenómeno y especialmente de las mujeres que lo abrazan como expresión religiosa identitaria.

En este sentido, cabe considerar, por un lado, las situaciones que llevan a que los sujetos aquí aludidos acudan a estos espacios religiosos antes que a otros de carácter laico, y qué opciones socialmente disponibles tienen una vez que se encuentran en situaciones críticas. Y por otro, las citadas paradojas de género, que suponen una complejidad mayor a la dicotomía dominación-subordinación que puede desprenderse de una lectura del fenómeno, reducida a su carácter discursivo.

Como se vio, si bien las construcciones sexo-genéricas en este contexto parten de normas y preceptos patriarcales, las mismas son "habitadas" desde la potencialidad que contienen, en lo que supone el acceso a una esfera comunitaria, a posiciones de liderazgo, y como respuestas a momentos de fuertes crisis existenciales, funcionando así como estrategias de supervivencia.

\section{Bibliografía}

Abélès, M y Badaró, M. (2015). Los encantos del poder. Desafios de la antropología política, Buenos Aires, Argentina: Siglo XXI.

Algranti, J. (2007). La política en los márgenes: estudio sobre los espacios de participación social en el neopentecostalismo. Caminhos, Goiania, 5(2), 361-380. 
Austin-Broos, D. (2003). The Anthropology of conversión: An Introduction. En: Bucker y Glazier (eds.). The Anthropology of religious conversion. England: Rowman \& Littlefield Publishers.

Bastian, J-P. (1997). La mutación religiosa de América Latina. Para una sociología del cambio social en la modernidad periférica. México D.F, México: FCE.

Biela Dias, T. (2019). Do púlpito ao palanque: o argumento da liberdade religiosa e a cura gay em perspectivas evangélicas conservadoras. Religare, 16(1), 117-139.

Bruner, J. (2006). Actos de significado. Madrid, España: Alianza.

Butler, J. (2001). Mecanismos psíquicos del poder. Teorías sobre la sujeción. Madrid: Ediciones Cátedra, Universitat de Valéncia Instituto de la Mujer.

Campos Machado, M. (2005). Representações e relações de gênero nos grupos pentecostais, Estudos Feministas Florianópolis, 13(2), 387-396.

Campos Machado, M; Lins de Barros, M. (2009). Gênero, geração e classe: uma discussão sobre as mulheres das camadas médias e populares do Rio de Janeiro. Estudos Feministas, Florianópolis 17(2), 369-393.

Campos Machado, M.; Delvalhas, F.; Zucco, L.; Neto, P. (2011). Homossexualidade e Igrejas Cristãs no Rio de Janeiro, Rever, 11(1), 75-104.

Carbonelli, M. (2014). Evangélicos, globalización y política en Argentina. Intervenciones públicas y misión divina, Civitas, Dossiê: Religião e globalização, 14(3), 504-522.

Carozzi, M.J; Frigerio, A. (1994). Los estudios de la conversión a nuevos movimientos religiosos: perspectivas, métodos y hallazgos, En: Carozzi y Frigerio (comps.) El estudio cientifico de la religión a fines del siglo XX. Buenos Aires, Argentina: CEAL

Chong, K. (2006). Negotiating patriarchy. South Korean Evangelical Women and the Politics of Gender. Gender \& Society, 20(6), 697-724.

Clifford, J. (1998). A experiencia etnográfica. Antropologia e Literatura no século XX, Rio de Janeiro, Brasil: UFRJ.

Das, V. (1997). Sufrimientos, teodiceas, prácticas disciplinarias y apropiaciones. International Social Science Journal. 49(154).

Douglas, M. (1978). Simbolos naturales. Exploraciones en cosmologia. Madrid: España: Alianza.

Frigerio, A. (1994). El pentecostalismo en Argentina. Buenos Aires, Argentina: Editor de América Latina.

Frigerio, A. (2002). El estudio de la religión desde la perspectiva de los movimientos sociales: sus aportes al análisis de la construcción de identidades religiosas. Ponencia presentada en GT Religiäo e Sociedade. XXVI Encontro Anual da ANPOCS. Caxambu, Brasil.

Goffman, E. (2001). Internados. Ensayos sobre la situación social de los enfermos mentales. Buenos Aires, Argentina: Amorrortu.

Jimeno, M.; Pabon, C.; Varela, D.; Díaz, I. (eds.) (2016). Etnografías contemporáneas III: las narrativas en la investigación antropológica. Bogotá, Colombia: Universidad Nacional de Colombia.

Jones, E.; Carbonelli, M. (2012). Evangélicos y derechos sexuales y reproductivos: actores y lógicas políticas en la Argentina Contemporánea. Ciências Sociais Unisinos, 48(3), 225-234.

Mafra, C. (1998). Gênero e estilo eclesial entre os evangélicos, Em: Fernandes, R. C., Sanchis, P., Velho, O., Carneiro, L.P., Mariz, C., Mafra, C., Novo Nascimento. Os evangélicos em casa, na Igreja e na Politica. Rio de Janeiro, Brasil: MAUAD.

Mafra, C. (2012). O percurso de vida que faz o gênero: reflexôes antropológicas a partir de etnografias desenvolvidas com pentecostais no Brasil e em Moçambique. Religião e Sociedade, Rio de Janeiro, 32(2), 124-148.

Mahmood, S. (2005). Politics of piety: the Islamic revival and the feminist subject. New Jersey, USA: Princeton University Press.

Martin, B. (2003). The Pentecostal Gender Paradox: A Cautionary Tale for the Sociology of Religion, In: Fenn, R.K (ed.) The Blackwell Companion to Sociology of Religion. Oxford: Blackwell Publishing. 
Mosqueira, M. (2014). "Santa rebeldia". Construcciones de juventud en comunidades pentecostales del Area Metropolitana de Buenos Aires. Tesis doctoral. Facultad de Ciencias Sociales, Universidad de Buenos Aires, Argentina.

Ortner, Sh. (1995). Resistance and the Problema of Etnographic Refusal. Society for Comparative Study of Society and History, 37(1), 173-193.

Sachs Norris, R. (2003). Converting to What?: Embodied culture and the Adoption of New Beliefs, En: Bucker \& Glazier (eds.). The Anthropology of religious conversion, England: Rowman \& Littlefield Publishers.

Scott, J. (1996). El género: Una categoría útil para el análisis histórico. En: Lamas (Comp.) El género: la construcción cultural de la diferencia sexual. México: PUEG

Semán, P. (2001). Cosmológica, holista y relacional: una corriente de la religiosidad popular contemporánea, En: Ciencias Sociales y Religión/ Ciências Sociais e Religião, 3(3) pp. 45-74.

Tarducci, M. (1994). O Senhor nos libertou: gênero, família e fundamentalismo. Cadernos Pagu, 3, 143-160.

Tarducci, M. (1999). Fundamentalismo y relaciones de género: 'Aires de familia' más allá de la diversidad, En: Ciencias Sociales y Religión/Ciências Sociais e Religião, Porto Alegre, 1(1), 189-211.

Tarducci, M. (2001). Estudios feministas de religión: una mirada muy parcial. Cadernos Pagu, 16, 97-114.

Weber, M. (2004). Economia y sociedad. Esbozo de sociología comprensiva. México: FCE.

Wynarczyk, H. (2011). Sal y Luz a las naciones. Evangélicos y politica en la Argentina (1980-2001). Buenos Aires, Argentina: Instituto Di Tella, Siglo XXI.

Wynarckzyk, H. (2014). Tres evangelistas carismáticos. Omar Cabrera, Héctor Aníbal Giménez, Carlos Annacondia. Buenos Aires, Argentina: FIET/Prensa ecuménica.

Zigon, J. (2007). Moral breakdown and the ethical demand: A theoretical framework for an anthropology of moralities. Anthropology Theory, 7(2),131-150.

\section{Notas}

1 La investigación en la cual se enmarca el presente artículo contó con una beca de posgrado de la ANII (Agencia Nacional de Investigación e Innovación) bajo el código POS_NAC_2017_1_141433.

2 Los dos yernos del dirigente y fundador de MVN, ocupan puestos en el gobierno: Álvaro Dastugue como diputado reelecto por el departamento de Canelones, y Gustavo “Gavo" Silveyra en la Dirección de Apoyo al Liberado dependiente del Ministerio del Interior (también candidato a diputado en el período electoral anterior).

3 Ondas de Amor y Paz arribó a Uruguay en 1989 a las ciudades de Colonia y Carmelo (Wynarczyk, 2014). Luego de un corto tiempo en la primera de estas, el matrimonio de los pastores Márquez-Molina se trasladó a Montevideo, donde fundaron Misión Vida para las Naciones alrededor de siete años después.

4 Una "institución total" es un "lugar de residencia o trabajo, donde un gran número de individuos en igual situación, aislados de la sociedad por un periodo apreciable de tiempo, comparten en su encierro una rutina diaria, administrada formalmente" (Goffman, 2001, p.13).

5 En Argentina se encuentra en San Juan; en Brasil en la localidad de Leme, São Paulo; en Chile en Coquimbo y en Haití en Puerto Príncipe.

6 Dicho relato se enmarca en la celebración por el Día Internacional de la Mujer llevada a cabo el sábado 9 de marzo en el templo principal de MVN, la cual a diferencia del año anterior no implicó la intervención en la marcha con cartelería anti-feminista, sino que se limitó a una merienda colectiva con tres testimonios públicos sobre "hechos milagrosos" y música cristiana. El testimonio público que siguió al de Noelia fue en contra del aborto. En este caso, subió al púlpito una mujer con un bebé, dos niños y su pareja, y relató cómo fue que decidió continuar con su embarazo a pesar de que les profesionales de la salud la instaran a abortar tras detectar que su feto tenía malformaciones, dando a luz a un bebé sano. Y el último testimonio fue el de una "mujer emprendedora" que incentivaba al enriquecimiento económico.

7 Efesios 5:23 "porque el marido es cabeza de la mujer, así como Cristo es cabeza de la iglesia, la cual es su cuerpo, y él es su Salvador”. 